\title{
Creative Computer
}

Graphics

\section{ANNABEL JANKEL and ROCKY MORTON}

\section{Creative Computer Graphics}

celebrates the beauty and dynamic visual power of images created with computer technology. From the pioneering efforts of the 1950 s to the current spectacular achievements in the US, UK, France and Japan, this book explores the fascinating technology used to create these stunning visuals. It describes, and lucidly explains, the part played by artists, scientists,

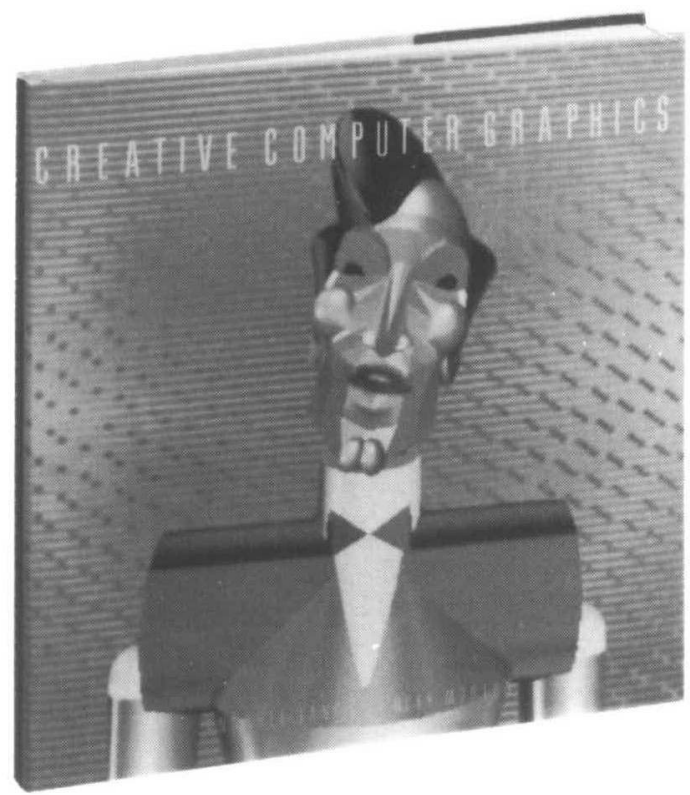
programmers and technicians in the creative process, and carefully interprets the necessary computer terminology for the non-specialist reader.

Linking the description of methods with striking examples and illustrations, the book traces the subject's history, assesses the current state of the art and looks forward to future developments. Through Creative Computer Graphics all kinds of readers can deepen their appreciation both of the beauty of computer generated images, and the genius and endless capabilities of the methods used to produce them.

'A captivating book ...'

Personal Computer World

'... its real value is in demonstrating the breadth of applications for graphics . . . in engineering design, simulation, medicine, architecture. ..'

The Engineer

'... should be in the library of any school or department with an interest in art or computing.'

Times Higher Education Supplement

'... splendidly illustrated and gives a good account of the struggles of an emerging medium...'

New Scientist

£15.95 net 


\section{Information for Contributors}

1. Manuscripts must be written in English. All manuscripts will be referred to acknowledged experts in the subject. Only those receiving favourable recommendations from the referees will be accepted for publication. Manuscripts may be sent to any Board member, any Associate Editor or the Editor.

2. The typescript should be double spaced, on one side of good grade paper, allowing a reasonable left-hand margin. An original and two copies should be submitted with the author's full postal address, position and affiliations.

3. The title and section headings should highlight the significant points. A short abstract should precede the main text.

4. One copy of photographs, prints or transparencies of good quality and unmarked should be submitted. Where lines or lettering are to appear on the photograph, an additional print should be supplied appropriately marked. Each should have, lightly written on the back, the author's name, the figure number and an indication of which is the top of the picture.

5. One copy of each line diagram should be submitted at approximately twice final size and unlettered. Diagrams must be drawn in indian ink on plain white or transparent paper. A second copy should be supplied with lettering included. The author's name and the figure number should be written on this copy.

6. Tables should be typewritten on separate sheets. Avoid, where possible, very wide tables.

7. References and footnotes should be cited according to the Harvard (Author/date system), also known as the "British form". In the text, author and year are cited in brackets e.g. "... was found by McCarthy $(1980 ; 1980 a)$..." or "(Emmett et al. 1972)". Full references are listed in alphabetic order at the end of the paper. References are not numbered. An example of a reference list is:

DEUTSCH, C. - KLARSFELD, S. 1973 Phys. Rev. A7, 2081.

NICHOLSON, D. R. 1983 Plasma Theory, (John Wiley, New York).

OOMURA, H. et al. 1982 Res. Rep ILE, ILE-8207p.

OOMURA, H. et al. 1982a Trans. ANS, 43, 617.

Note that the year of publication appears after the author's name. If possible, all authors names should be listed in preference to "et al." If one author or team is referred to more than once in any year, the letters $a, b$, etc should be added after the year to distinguish the individual references.

8. Correction to proofs should be restricted to printers' errors only. Authors are entitled to 25 offprints of their article free of charge. Additional offprints may be purchased if they are ordered on the form sent with the proofs. 
Volume 4 Part 1 February 1986

A. J. Glass: Guest Editor-Selected papers from CLEO' 85

\section{CONTENTS}

\section{H. Hora: Foreword}

R. J. Jensen and Participants in the Los Alamos Advanced Laser Program: Los Alamos krypton fluoride laser program 3

H. Daido, M. Fujita, K. Terai, F. Miki, K. Nishihara, M. Murakami, K. Mima, S. Nakai, C. Yamanaka and A. Hasegawa: Observation of long life plasma generated in a cavity by $\mathrm{CO}_{2}$ lasers 17

J. Badziak, M. Borzecki, A. Chojnacka, Z. Dźwigalski, K. Janulewicz, R. Jarocki, A. Kalbarczyk, J. Kubicki, Z. Kurzyński, L. Perlinski, Z. Sikorski and J. Teter: Short-pulse $\mathrm{CO}_{2}$ laser systems for plasma investigation at the IPPLM 27

T. Yamanaka, T. Mochizuki, H. Azechi, H. Nishimura, M. Yamanaka, N. Miyanaga, H. Niki, E. Fujiwara, H. Shiraga, K. Okada, S. Sakabe, Y. Kato, Y. Kitagawa, M. Nakabsuka, K. Yoshida, Y. Izawa, T. Norimatsu, K. Mima, K. Nishihara, T. Yabe, S. Nakai and C. Yamanaka: Characteristics of plasmas imploded by $\omega, 2(w, 3 \omega)$ and $4 \omega$ lasers 43

L. A. Rosocha, P. S. Bowling, M. D. Burrows, M. Kang, J. Hanlon, J. Mcleod and G. W. York. Jr.: An overview of aurora: a multi-kilojoule KrF laser system for inertial confinement fusion 55

M. Tanimoto, A. Yaoita, I. Okuda, Y. Owadano, Y. Matsumoto and T. Kasai: Prospect of efficient high-power-density operation of $\mathrm{KrF}^{*}$-excimer for fusion driver: characteristics in $\mathrm{Kr}$-rich gas mixtures 71

H. Hora, J.-C. Wang and P. J. Clark: Increased gain of the lateral-injection free-electron laser and the use of clusters for amplification in the X-ray range 83

J. A. Sullivan and C. W. von Rosenberg, Jr.; High energy krypton fluoride amplifiers for laser-induced fusion 91

T. Guishen, Q. Peixia, L. Weiping and C. Youming: A master oscillator with three functions for laser fusion systems 107

S. Denus, A. Dubik, B. Kaczmarczyk, J. Makowski, J. Marczak, J. Owsik, Z. Patron and M. Szczurek: Optimized four-channel Nd:glass laser system for compression experiments 119

R. B. Wilcox: Photoconductive switch pulse shaping device for the Nova master oscillator 141

M. C. Jackson, R. D. Long, D. Lee, N. J. Freeman: Development of X-ray streak camera electronics at AWRE 145

\section{(C) Cambridge University Press 1986}

Cambridge University Press, The Pitt Building, Trumpington Street, Cambridge CB2 1RP 32 East 57th Street, New York, NY 10022, USA

10 Stamford Road, Oakleigh, Melboume 3166, Australia

Printed in Northern Ireland by The Universities Press (Belfast) Ltd, Belfast BT6 9HF 